\title{
DESIGN AND DEVELOPMENT OF STEERING SYSTEM OF AN ALL-TERRAIN VEHICLE
}

\author{
V.K. Saini \\ Professor, Mechanical Engineering, IMS Engineering College, Ghaziabad \\ Abhishek Saxena \\ Assistant Professor, Mechanical Engineering, IMS Engineering College, Ghaziabad \\ Ujjwal Tripathi, Shivam Chaudhary, Vikas Rana, Yashank Saini \\ UG Scholar, Department of Mechanical Engineering, IMS Engineering College, Ghaziabad
}

\begin{abstract}
The Study named "Design and Development of Steering System of an All Terrain " is to search out the acceptable and economical steering mechanism for an all terrain vehicle. For this choice numerous parameters area unit thought about. The geometry for steering is choosed to be Anti- Ackerman geometry. It's choosed to convert the rotational motion into travel motion from Rack and Pinion. The steering column used is of fabric AL6082-T6. The steering wheel is self-designed for the optimization of its size and to scale back its weight. Throughtout the look of wheel technology don't seem to be compromised. The motion of steering wheel is transferred to the tires with the assistance of a combine of tie rods. The tie rods and wheel hubs are connected with self-designed steering arms.
\end{abstract}

Keywords: Rack and pinion gearbox, AntiAckerman steering geometry, Tie rods, Steering arm, Steering wheel, All-terrain vehicle, Steering column.

\section{INTRODUCTION}

The Steering system is that the key interface between the driving force and also the vehicle. Steering system is a mechanism want to management the trail followed by the vehicle. The operation of the Steering system is to turn the front wheels whenever driver offers the inputs so as to produce all directional control of the vehicle. The particular angles of steering are modified by the geometry of the suspension, reactions of powertrain and the steering system geometry if the vehicle is front wheel drive.
The rack and pinion system is wide employed in the passenger thanks to the benefits sorts of an easier style and better suitability of the front wheel drive system and adaptability to vehicles without frames. The Gearbox is the main element or we are able to say the first suggests that for the numerical reduction between the rotational input from the steering wheel and rotational output regarding the steering axis. The magnitude relation of steering wheel angle to the wheels angle normally vary, but in general 15:1 for business vehicles to 4:1 for racing cars[5]. At the initial stage, all Rack and Pinion systems are available that have fixed ratios and any change in geometry leads to change in the ratios. Today, the variable gear ratios are available in rack and pinion systems which can vary with change in steer angle.

The lateral acceleration produced by the gearbox is imparted through linkages to steering arms on both the wheels. The kinematic geometry of the relay linkages and steering arms is usually not a parallelogram, but rather a trapezoid to more closely approximate " Ackerman" inner wheel angle is greater than the outer wheel while turning[2].

In this study Anti-Ackerman geometry is used in which outer wheel steers to greater angles than the inner wheels other aspects remain the same[3].

We made a comparison with our proposed designed vehicle from the data of a research paper given on the table below:

Table 1: Previous year steering parameter [5]

\begin{tabular}{|l|l|}
\hline $\begin{array}{l}\text { STEERING PARAMETER } \\
\text { (2018) }\end{array}$ & \\
\hline Steering ratio & $6.1: 1$ \\
\hline
\end{tabular}


International Journal of Engineering Applied Sciences and Technology, 2020

Vol. 5, Issue 4, ISSN No. 2455-2143, Pages 565-570

Published Online August 2020 in IJEAST (http://www.ijeast.com)

\begin{tabular}{|l|l|}
\hline Turn lock to lock rev. & 1.5 \\
\hline Geometry & Ackerman \\
\hline Column & Modified tata nano \\
\hline Rack and pinion & Tata nano \\
\hline Steering wheel diameter & 8 "' \\
\hline
\end{tabular}

\section{METHODOLOGY}

The systematic, theoretical analysis of methods used to study and calculate the required parameters.

Following steps were involved for design and fabrication of steering system:

Analysis of Previous year's Vehicles:

a) By defining the Objective for New vehicle.

b) Through Market Survey for the Components used.

c) By Steering Geometry Iterations.

d) Design Validation

e) Steering system parts fabrication.

f) Steering system Assembly

\subsection{Objective for New Vehicle}

The main objective was to make a better ATV than the previous years and for that the following parameters were decided for the new vehicle which are as follows:

a) Outer Turning Radius -: $1.5 \mathrm{~m}$

b) Lesser Scrub radius

c) Less Unsprang Mass

d) Modified Steering Column for weight reduction.

e) Anti-Ackerman Steering Geometry.

f) As per driver's comfort the steering wheel dimensions are optimized.

\subsection{Market Survey}

Market survey is very much necessary to select the right components. It will reduce the risk involved in making the decisions.

After market Survey was done following Components were selected:
a) Customized Rack and Pinion Gearbox. $(10: 1)$
b) $\mathrm{Al}$ 6082-T6 for Steering Column.
c) Stainless Steel(SS) 304 Pipes for Tie rods.
d) $\mathrm{Al}$ 6082-T6 for the Steering Arms.

\subsection{Steering Geometry}

The Anti Ackerman steering geometry was selected for the vehicle because this geometry enables the vehicle to turn about the common centre i.e. without skidding of the road wheels or tires. The Anti
Ackerman geometry prevents skidding of the inner wheel that occur at low speed turning. This geometry provides better control for high-speed and mediumspeed maneuvering.

Table 2: Rack and Pinion

\begin{tabular}{|l|l|}
\hline Parmeters & Values \\
\hline Size of rack & 15 inches \\
\hline Size of rack (eye to eye) & 14 inches \\
\hline Centre to lock travel & 2.24 inches \\
\hline Lock to lock travel & 4.48 inches \\
\hline Radius of pinion & 0.53 inches \\
\hline
\end{tabular}

The parameters for the vehicle that were set shown within the table below:

Table 3: Vehicle design parameter

\begin{tabular}{|l|l|}
\hline Design Parameters & Values \\
\hline Wheelbase (b) & 53 inches \\
\hline Trackwidth (a) & 53 inches \\
\hline Rack Length & 14 inches \\
\hline Ground clearance & 13 inches \\
\hline KPI to KPI distance (c) & 44.74 inches \\
\hline Scrub Radius & 3.52 inches \\
\hline $\begin{array}{l}\text { Ackerman geometry: All four wheels } \\
\text { have the same centre of turning thus } \\
\text { avoid the slipping of wheels and } \\
\text { reduce tyre wear. }\end{array}$ \\
\hline
\end{tabular}

Figure -1: Ackerman geometry

In Ackerman geometry the inner wheel angle is greater than that of the outer wheel. While in Anti Ackerman, the outside wheel turns more than the inner wheel. In this geometry, the rack is placed ahead of the front axle. In Ackerman geometry, if we draw a line from the steering arms then they will meet at the line drawn at the extension of rear axle during turning, that point is the instantaneous center about which the whole vehicle turns without skidding. In Anti Ackerman, same thing happens but in virtually opposite direction[4]. 


\subsubsection{Inside and Outside Steering Angle}

After varied iterations on Lotus Shark software and on sensible physical model, steering angles were calculated as given below:

$\Phi=48.43^{\circ} ; \Theta=31.46^{\circ}$

Where, $\Phi=$ Outer tyre angle

$\Theta=$ Inner tyre angle

$R_{o f}=\frac{b}{\sin \phi}+\frac{a-c}{2}$

Putting all the values, we get

$R=1.82 \mathrm{~m}$ (turning radius)

\subsubsection{Steering Ratio}

It is the magnitude relation of angle turned by steering wheel in lock positions to the sum of total steering angle of tires so[3],

Total angle turned by steering wheel

$=$ track $w i d t h /(2 \times 3.14 \times$ pinion radius $)$

$=475.583 \mathrm{deg}$.

Steering ratio $=\left\{\begin{array}{c}\begin{array}{c}\text { Total angle turned by } \\ \text { Steering wheel }\end{array} \\ \begin{array}{c}\text { Total angle turned by } \\ \text { Wheels }\end{array}\end{array}\right\}(2)[4]$

Steering ratio $=\mathbf{5 . 9 5 2 : 1}$

\subsubsection{Position of rack}

Several iterations were made to decide the position of rack on LOTUS Shark Simulation software in step with to the steering angles, the subsequent informations were obtained:

a) Height of rack $=17$ inches from Ground

b) Length of Steering arm from KPI to Pivot Point $=4.1$ inches

c) Ackermann angle $=($ kpi to kpi distance $) /$ ( $2 \times$ wheel base)

d) Ackerman Angle $=24.36^{\circ}$

e) Ackerman Percentage $=58 \%$ (Calculated from Lotus Shark software)

f) Travel on rack $=4.48$ inches (lock to lock).

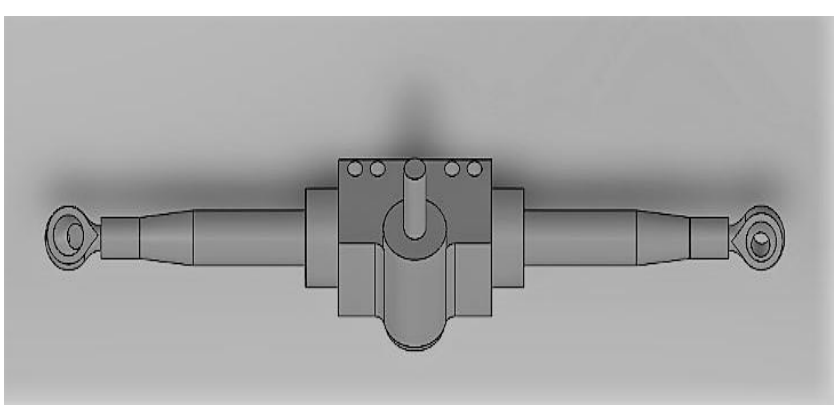

Figure -2: Rack and Pinion

\subsubsection{Tie Rod Length}

Steering Arm measurement or Length $=4.1$ " (After various iterations done on LOTUS SHARK software and manually both to acquire the required angles).

The tie rods and steering arm plane were not same, tie rods are inclined at some angle that was $17 \mathrm{deg}$ downwards from horizontal and 5deg towards forward which means tie rods are not parallel to front axle (as per the design of vehicle).

Therefore, the tie rod length $=14.7$ inches

The suspension arms (A-arms) used in the vehicle are parallel to each other and of equal length i.e. the I Centre of the A-arms are at infinity. The tie rods have to be parallel to suspension A-arms so that during bump the I-Centre of tie rods should also meets the ICentre of A-arms at infinity, this was to reduce the bump. In this way the arc traveled by the tie rods and the arms were equidistant to each other during the travel of suspension and there was no force generated along the rack to produce bump steer[5].

\subsubsection{Determination of Steering Effort}

It is the amount of effort made by the driver for turning the steering wheel. This can either be determined in static condition or in dynamic conditions. When the vehicle is stationary, the steering effort was maximum[3].

Sprung mass $=178 \mathrm{~kg}$

Unsprung mass $=52 \mathrm{~kg}$

Centre of gravity $=22$ inches from rear

Taking moment about rear

$178 * 22=\mathrm{RA} * 53$

$\mathrm{RA}=73.88 \mathrm{~kg}$

Reaction at each tire

$=(\mathrm{RA} / 2+$ unsprung mass on each tyre $) * 9.81$

$=489.911 \mathrm{~N}$

For static condition, the forces in all directions are in equilibrium

$\Sigma \mathrm{Fx}=0 ; \mathrm{FL}=\mathrm{FR} \ldots . .(1)$

$\Sigma \mathrm{Fy}=0 ; \mathrm{N}=\mathrm{mg}$ 
The tires are used in mud so the coefficient of friction between tires and rolled gravel ground is 0.6 (data provided by different tire manufacturers)

The friction force at the tire is

$=\mu^{*}$ Reaction at each tire

$=293.9644 \mathrm{~N}$

When we turn the steering wheel the torque will transfer to the pinion and then to the steering arms, this torque should be equal to or greater than that of the frictional resistance of the ground which would be able to turn the tires.

From above, the torque on steering arm is calculated by multiplying length of steering arm with the friction force.

Steering Arm $(\mathrm{SA})$ torque $=293.9644 * 4.1 * .0254=$ $30.6134 \mathrm{~N}-\mathrm{m}$

Force perpendicular to steering arm (FS1)

FS1 $=30.6134 / 0.10414=293.9644 \mathrm{~N}$

Now the tie rod is not in the same plane of steering arm and also not parallel to front axle so components of this force is taken Therefore, component of force below tie rod in the plane of steering arm is FS2 FS2 $=\mathrm{FS} 1 / \cos 25=324.3539 \mathrm{~N}$

Since the tie rod is at an angle of $16.3 \mathrm{deg}$ above from the plane of FS2 (According to rack placement and steering arm plane)

$\mathrm{FST}=\mathrm{FS} 2 / \cos 21.38=348.3245 \mathrm{~N}$

Force along rack (Frack)

Frack $=$ FST $/ \cos 21.38=374.06663 \mathrm{~N}$

Now, torque exerted on the pinion

$=$ Frack $*$ radius of pinion

$=\mathbf{5 . 0 3 8 6} \mathrm{N}-\mathrm{m}$

\section{Torque on steering wheel $=$ Torque on pinion}

Steering wheel torque $=5.0386 \mathrm{~N}-\mathrm{m}$

The amount of force required on the steering wheel is calculated by dividing the torque by the radius of steering wheel[5].

Steering effort $=5.2467 /(0.1016)$

Steering effort $=\mathbf{4 3 . 4 3 6 8} \mathrm{N}$

In static condition, this much amount of steering effort will be applied by the driver to steer the tire whereas the less effort will be required in dynamic condition than static.

\subsubsection{Oversteer or Understeer (nature of steering)}

Oversteer - It is the condition once the vehicle turns over the angle provided by the driving force through handwheel throughout cornering. This is often primarily happening once the rear tires losses their traction before the front tires because of the centrifugal force functioning on them[4].

Understeer - It is the condition once the vehicle turns less than the angle provided by the driving force through steering wheel during cornering at large speeds and smaller curves. In this case, the vehicle follows a larger curve for cornering then it actually should. In this, the driver has to steer the handwheel over the required angle for making the turn[4].

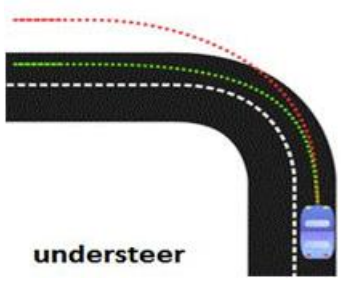

Wikipedia

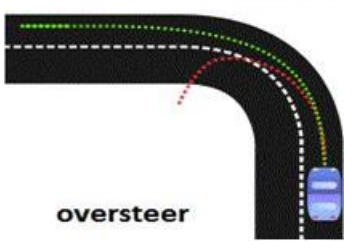

Image credit:
Figure 3: Understeer \& Oversteer

Whenever the vehicle takes a turn an outward lateral force is acting on the vehicle due to centrifugal effect also known as the cornering force.

Sum of lateral forces is equal to mass of vehicle time's centripetal acceleration.

$\mathrm{FYR}=$ Rear axle lateral force \& FYF $=$ front axle lateral force. Now, FY = FYF + FYR

Sprung mass of vehicle $=178 \mathrm{~kg}$ Sprung mass at front axle and rear axle $\mathrm{MF}=78.32 \mathrm{~kg}$

$\mathrm{MR}=99.68 \mathrm{~kg}$

At fixed radius of $2.55 \mathrm{~m}$ and different velocities values of FYF and FYR are as follows

At $\mathrm{v}=0 \mathrm{~m} / \mathrm{s}$

$\mathrm{FYF}=\mathrm{Mf} \times \mathrm{V} 2 / \mathrm{R}=0$

$\mathrm{FYR}=\mathrm{M} \times \mathrm{V} 2 / \mathrm{R}=0$

Similarly,

At $\mathrm{v}=1.39 \mathrm{~m} / \mathrm{s}$

$\mathrm{FYF}=71.85 \mathrm{~N}$

$\mathrm{FYR}=91.449 \mathrm{~N}$

At $\mathrm{v}=2.28 \mathrm{~m} / \mathrm{s}$

$\mathrm{FYF}=193.32 \mathrm{~N}$

$\mathrm{FYR}=246.0477 \mathrm{~N}$

At $\mathrm{v}=4.16 \mathrm{~m} / \mathrm{s}$

$\mathrm{FYF}=643.57 \mathrm{~N}$

$\mathrm{FYR}=819.09 \mathrm{~N}$

At $\mathrm{v}=5.55 \mathrm{~m} / \mathrm{s}$

$\mathrm{FYF}=1145.51 \mathrm{~N}$

$F Y R=1457.92 \mathrm{~N}$

At $\mathrm{v}=6.99 \mathrm{~m} / \mathrm{s}$

$\mathrm{FYF}=1817.05 \mathrm{~N}$

$F Y R=2099.41 \mathrm{~N}$ 
Now Average values

$\mathrm{FYF}=774.26 \mathrm{~N}$.

$\mathrm{FYR}=942.78 \mathrm{~N}$.

Under cornering conditions, in which the tire must must develop a lateral force, the tire will also experience lateral slip as it rolls. The angle between its direction of healing and its direction of travel is known as slip angle[3].

These are illustrated in figure below:

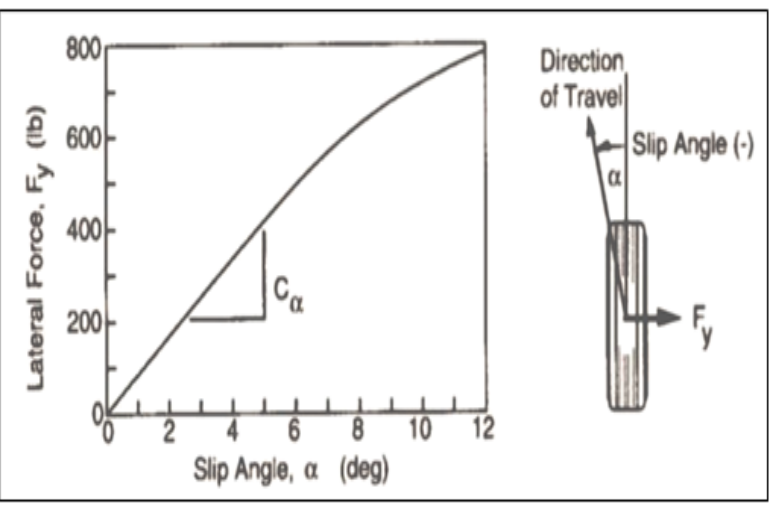

Figure - 4: Lateral Force vs. Slip Angle Graph

From the above graph the values of slip angle are interpolated as

$\alpha \mathrm{f}=2 \mathrm{deg}$

$\alpha \mathrm{r}=2.7 \mathrm{deg}$

Cornering stiffness $(\mathrm{C} \alpha)=\mathrm{Fy} / \alpha$

$\mathrm{C} \alpha \mathrm{f}=774.26 / 2=387.13 \mathrm{~N} / \mathrm{deg}$

Cor $=942.78 / 2.7=349.17 \mathrm{~N} / \mathrm{deg}$

Weight on front axle $(\mathrm{Wf})=\mathrm{MF} \times 9.81=768.31 \mathrm{~N}$

Weight on rear axle $(\mathrm{Wr})=\mathrm{MR} \times 9.81=977.86 \mathrm{~N}$

\section{Oversteer condition}

If $(\mathrm{Wr} / \mathrm{Car})>(\mathrm{Wf} / \mathrm{Caf})$ then vehicle will Oversteer otherwise it will have tendency of Understeer[6].

$$
(\mathrm{Wr} / \mathrm{Car})=2.8 \quad(\mathrm{Wf} / \mathrm{Caf})=1.9
$$

From above we see that the value satisfies the condition of oversteer, therefore it has the tendency of oversteering during cornering.

\subsubsection{Materials Used For Different Steering Parts}

Table-4: Materials used for different parts

\begin{tabular}{|l|l|}
\hline Components Used & Material Used \\
\hline Steering Arm & AL6082-T6 \\
\hline Tie rod & Stainless steel 304 \\
\hline
\end{tabular}

\begin{tabular}{|l|l|}
\hline C clamp & Stainless steel 304 \\
\hline Rack & EN 24 \\
\hline Steering Column & AL6082-T6 \\
\hline
\end{tabular}

\section{CONCLUSION}

The main objective of coming up with a good mechanism for associate in nursing ATV (all-terrain vehicle) was to accomplished with the appliance of engineering principles and with the employment of Simulation Software like LOTUS SHARK, the vehicle's steering system was designed for optimal performance. The Design was valid in dynamic conditions and effective changes were done with improvements in design. In this study, steering ratio was achieved 5.925:1 which is better than target of 7:1 and great improvement from previous steering ratio. The system was designed to scale back the bump steer as much as it was possible to achieve it in give condition. Bump steer within the vehicle is sort of negligible.

Various factors and parameters like suspension, weight distribution, and transmission system were thought-about whereas coming up with steering system. For improvement of steering system, the varied iterations were allotted on software and manually each for the most effective appropriate resolution that fulfills all the necessities of the vehicle.

As it involves a great deal of unknown variables, certain parameters were assumed regarding the geometry, hit and trail method was used to performed the iterations and then checked whether the assumption of the system meets the objective or not. Perfect Ackerman geometry is quite hard to achieve so It was tried to keep as close as possible.

This paper shows all the calculations that were created to design a steering system of ATV. This steering system was fabricated. This fabricated steering system was tested on the ATV that meet the complete set objective for this ATV.

\section{REFERENCES}

[1] G.B.S. Narang - Automobile Engineering

[2] Carroll Smith - Tune to Win

[3] Thomas D Gillespie - The Fundamentals of Vehicle Dynamics (page 275- 304).

[4] William F. Milliken and Douglas L. Milliken -: Race Car Vehicle Dynamics; 
[5] Dr. V.K. Saini, Prof. Sunil Kumar, Amit Kumar Shakya, Harshit Mishra (2018), Design Methodology for Steering System of all ATV. International Research Journal of Engineering and Technology, 4(5).

[6] Dhiraj Malu, Nikhil Katare, Suraj Runwal, Saurabh Ladhe (2016), Design Methodology for Steering System of an ATV. International Journal of Mechanical Engineering and Technology, 7(5), pp. 272-277. 